\title{
Experimental and numerical study of a fractured marble epistyle restored with layers of titanium bars
}

\author{
S.-K. Kourkoulis ${ }^{1, a}$, M. Mentzini' ${ }^{2}$, and E. Ganniari-Papageorgiou ${ }^{1}$ \\ ${ }^{1}$ School of Applied Mathematical and Physical Sciences, Dept. of Mechanics, National Technical \\ University of Athens, 5 Heroes of Polytechnion Avenue, 15773 Zografou, Athens, Greece \\ ${ }^{2}$ Committee for the Conservation of the Acropolis Monuments, Acropolis, Athens, Greece
}

\begin{abstract}
The mechanical behaviour of fractured prismatic marble architraves (epistyles) is evaluated in the present study both experimentally and numerically. The study is based on a recently introduced method for the calculation of the reinforcement required for joining together fractured structural elements of ancient monuments. The experimental assessment includes the construction of an accurate model of the most seriously damaged architrave of the north colonnade of the Parthenon Temple in a scale 1:3. The epistyle is considered symmetrically fractured at its mid-plane and it is restored with three horizontal layers of titanium bars. A multi-point bending arrangement was designed including a system of double T-beams and steel rollers in order to approach in an optimum manner the action of the uniformly distributed load exerted on the epistyle in its original position. A numerical analysis followed in an effort to study the parameters influencing the behaviour of the epistyle. The numerical model simulated accurately all the geometrical details of the experimental model, the load application mode and the mechanical characteristics of the three materials used for the restoration (marble, titanium and interposed cementitious material). The analysis enlightened interesting points concerning the location of the regions of the structure more susceptible to failure.
\end{abstract}

\section{Introduction}

Restoring ancient monuments is an extremely complicated multidisciplinary scientific task and the correct design of the interventions necessitates reliable data concerning the mechanical behaviour of the materials. Towards this direction (and taking into account the scarcity of specimens) it appears that a combination of experimental and numerical analyses is very helpful since it can provide valuable information about the locations of the structure more susceptible to failure, and also it can lead to better understanding of the behaviour of the whole structural system.

For the structural restoration of the monuments of the Acropolis of Athens a pioneer method has been developed, already from the early seventies, for the calculation of the required reinforcement for joining together multi-fragmented structural members. The method, based on the use of titanium bars in combination with a suitable cementitious material, permitted the reduction of the intervention on the authentic material in comparison to older approaches [1-5].

a e-mail : stakkour@central.ntua.gr

This is an Open Access article distributed under the terms of the Creative Commons Attribution-Noncommercial License 3.0, which permits unrestricted use, distribution, and reproduction in any noncommercial medium, provided the original work is properly cited. 
Nowadays the above method is used widely for the restoration of a number of multi-fragmented epistyles of the north colonnade of the Parthenon Temple. The epistyles are subjected to bending by distributed loads due to their own weight and the weight of the superimposed structural members. The majority of these epistyles have been seriously damaged by an explosion during the siege of Acropolis by Morosini (1687). Unsuccessful earlier restoration projects (1923-1933) led to the appearance of additional structural problems (intrusion of moisture, appearance of funguses, corrosion and inflation of the iron joints and further marble disintegrations).

Recently the reinforcement method was assessed both experimentally and numerically [6-10]. The analyses revealed the critical regions, where the maximum stress and strain discontinuities appear and enlightened the influence of the geometrical characteristics of the reinforcing bars and the crucial role of the constitutive law governing the mechanical behaviour of the intermediate layer of cementitious material. It became clear that the method for the calculation of the reinforcement required should be studied further before definite conclusions are drawn. In this direction a more thorough experimental and numerical investigation of the problem of restoring symmetrically fragmented epistyles is undertaken in the present study. The main target is the validation of previous numerical models [7-10] and the quantification of the influence of some critical parameters related to the reinforcing bars (number of bolted titanium bars, thread shape, anchoring length).

\section{Experimental procedure}

An accurate model of a typical epistyle of the north external colonnade of the Parthenon Temple on the Acropolis of Athens was tested. The specimen was considered centrally and vertically fractured into two pieces which were joined with the aid of three horizontal layers of threaded titanium bars (with two bars at each layer) placed in holes grooved along the axis of the member and filled with cementitious material. The required reinforcement was calculated according to a previously introduced method $[4,5]$. According to this approach the three layers were placed at distances 7, 20 and $30 \mathrm{~cm}$ from the bottom side of the epistyle. In Figure 1 one can see the respective parts of the model in the phase of its preparation. The model was constructed under a scale of 1:3 in order to avoid the influence of the size effect (length $\mathrm{x}=1.43 \mathrm{~m}$, height $\mathrm{y}=0.45 \mathrm{~m}$ and width $\mathrm{z}=0.18 \mathrm{~m}$ ). Special attention was paid for the accurate reproduction of all the geometrical details as well as the inclination of the material layers of the marble. The model was made from Dionysos marble. This material is used exclusively for the restoration project of the Parthenon (completion of damaged members and substitution of missing ones) since it has the nearest physical and mechanical properties to the Pentelic marble, used by ancient Greeks for the erection of the Temple [11].

The specimen was subjected to ten-point bending in

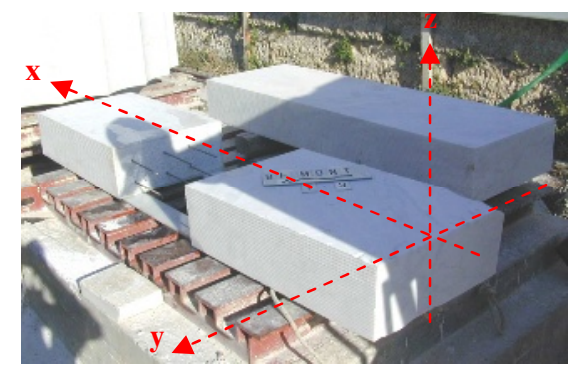

Fig.1. The two marble parts of the model during its construction. the Laboratory of Testing and Materials of the National Technical University of Athens resting on cubic marble blocks simulating the supporting abacuses. The load was exerted statically with the aid of a very stiff hydraulic frame of loading capacity $6 \mathrm{MN}$. It was applied through a system of double T-beams and steel rollers in order to approach in an optimum manner the action of the uniformly distributed load exerted on the epistyle in its original position. During the procedure the strains, the deflections and the opening of the crack were recorded through a measuring system including:

- 39 electrical strain gauges, suitably positioned at various strategic points at the front and bottom faces of the model (Figure 2a).

- 2 glass gauges positioned at the front face of the restored epistyle along the height of the central cross section at distances 2 and $14 \mathrm{~cm}$ from its bottom side for the immediate detection of the points at which crack extension first appears (Figure $2 b$ ). 
- 4 LVDTs of sensitivity $10^{-6} \mathrm{~m}$ (one at the bottom face of the model and specifically at the midpoint of its free span (Figure 2b) and three at distances 2.5, 7.5 and $12.5 \mathrm{~cm}$ from the right end of the epistyle (Figure 2c)) for the measurement of the elevations of the bottom side of the architrave.

- Suitable clip gauges placed at the bottom side of the model at its central cross section for the measurement of the Crack Opening Displacement (COD).

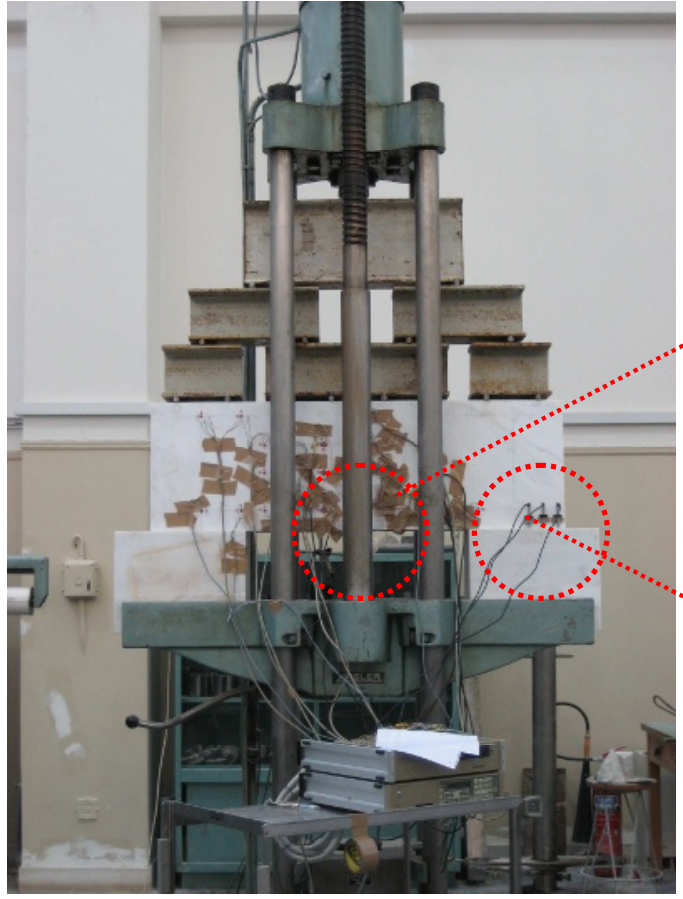

(a)

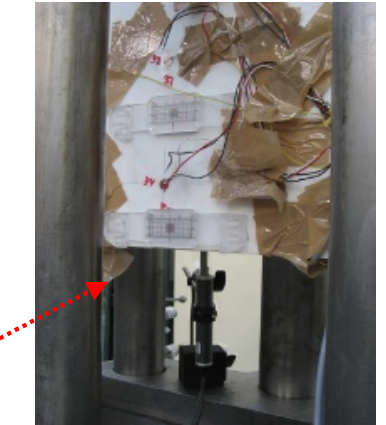

(b)

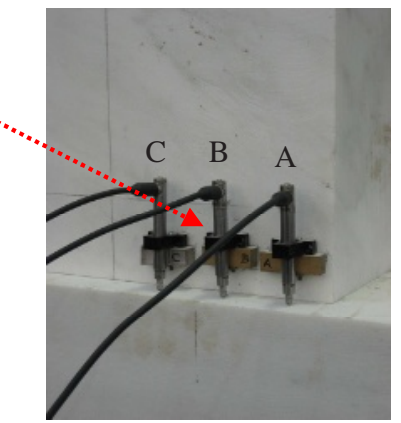

(c)

Fig.2. The specimen, the loading system and the strain-displacement measurement system just before the onset of the experimental procedure.

The overall behaviour of the model was considered satisfactory, since the architrave didn't fail for loads almost 130 times higher than its own weight. Although the initially designed maximum load was $480 \mathrm{kN}$ (the load causing yielding of the lowest layer of the reinforcing bars [12]) the load finally applied was $427 \mathrm{kN}$ due to an unpredictable warping of the uppermost double T-beam of the loading system. It is also to be mentioned that at a load equal to $115 \mathrm{kN}$ a non visible by naked eye crack appeared at the contact surface of the two main parts of the architrave as it was indicated by the respective glass gauges. As the load increased beyond $180 \mathrm{kN}$ the width of the crack increased to $1 \mathrm{~mm}$ and at a load level equal to $330 \mathrm{kN}$ the length of the crack extended up to almost the $3 / 4$ of the height of the epistyle. After the load was removed the width of the crack decreased to a value between 0.3-0.4 mm while its detectable length was equal to about $0.35 \mathrm{~cm}$ both at the front and the rear faces of the specimen. It is also to be mentioned that serious marble exfoliations were observed at the points closest to the edges of the supporting abacuses, where the so-called "fillet" ( according to the ancient Greeks) was sculptured, obviously due to high local stress concentrations.

The variation of the deflection of the lowest side of the architrave at its mid-span is presented in Figure 3, where it is seen that the deflection increases according to a more or less linear manner up to each plateau of the load and then it continues increasing in a similar way. Upon unloading it decreases to a permanent value of about $0.6 \mathrm{~mm}$. Two plateaus were recorded at loads equal to $35 \mathrm{kN}$ and $173 \mathrm{kN}$ (the deflections appeared to increase under almost constant load) indicating either failure 
or pull-out of one or more of the reinforcing bars. Similar observations are valid for the variation of the width of the crack at the contact surface of the two fragments of the architrave versus the applied load (Figure 4). Finally, the data obtained from the three LVDTs indicated that part of the beam resting on the abacuses lifted up slightly losing contact. Points A and B were lifted at loads equal to about $80 \mathrm{kN}$ and $300 \mathrm{kN}$, respectively. On the contrary point $\mathrm{C}$ was moved in the opposite direction indicating compression between the architrave and the abacuses. This situation should be considered carefully, since contact loss permits intrusion of dust or humidity between the abacuses and the epistyle.

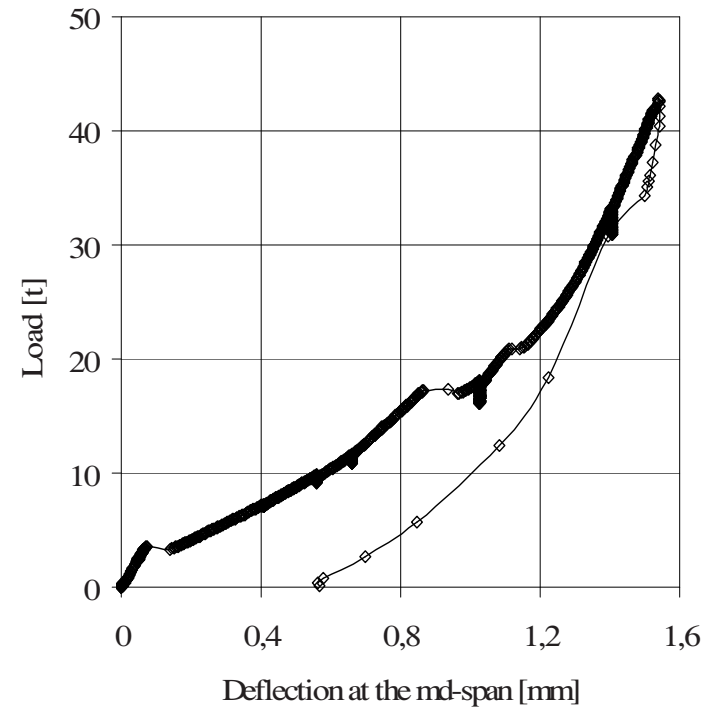

Fig.3. Load vs. deflection during the loadingunloading loop.

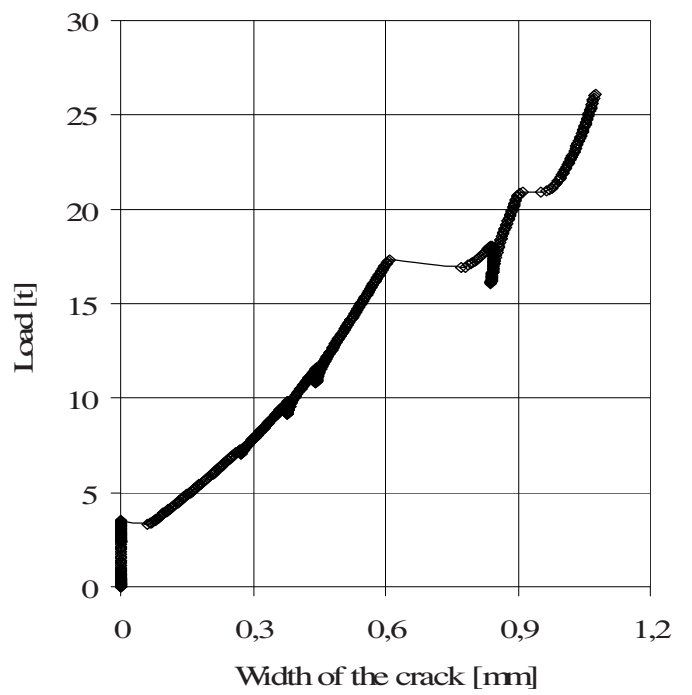

Fig.4. Load vs. width of the crack appeared at the contact surface of the two marble blocks.

In Figures 5 and 6 the axial and transverse strains (obtained from the strain gauges) are plotted along the lower horizontal layer of the reinforcement $(7 \mathrm{~cm}$ from the bottom side of the architrave) and along the height of the epistyle at the central cross section, respectively, for the maximum load

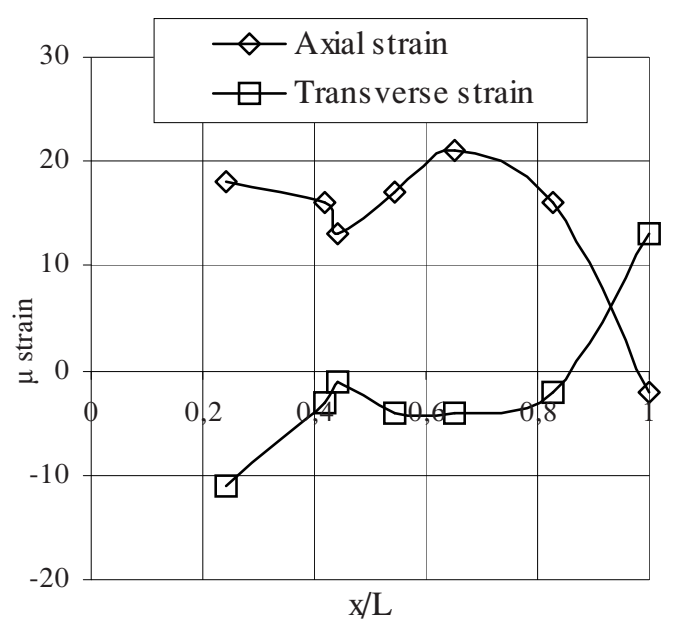

Fig.5. The axial and transverse strains along the lower reinforcement layer for the maximum load.

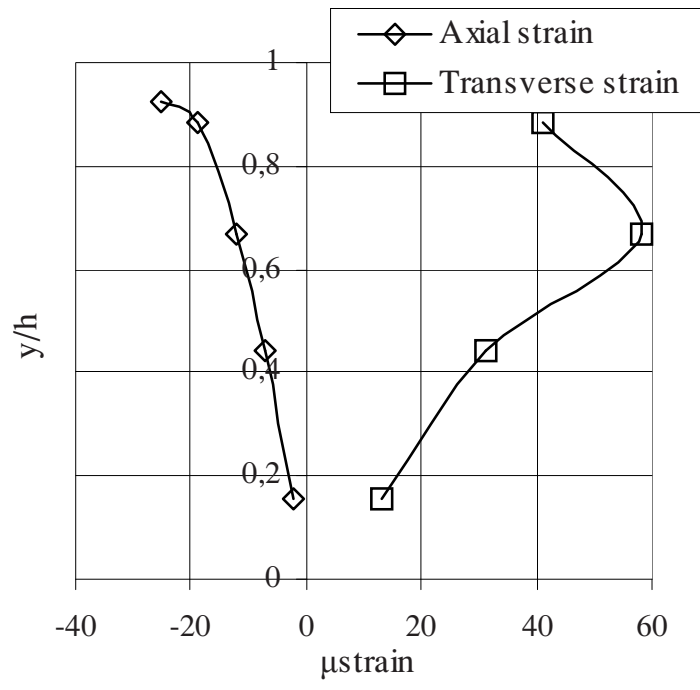

Fig.6. The axial and transverse strains along the height of the epistyle for the maximum load. 
reached $(427 \mathrm{kN})$. From Figure 5, it is seen that the axial strain attains high tensile values at the region near the fillets. From this point on these values are reduced following an almost parabolic curve up to their elimination at the region close to the central cross section of the model. Similar behaviour is observed for the strains along the other two layers of titanium bars. From Figure 6, it is seen that high compressive axial and tensile transverse strains appear all over the height of the model which are reduced abruptly as one moves towards the bottom side of the model.

\section{Numerical analysis}

A numerical analysis followed based on the Finite Element Method in an effort to study in a parametric manner the factors influencing the behaviour of the epistyle. The numerical model reproduced accurately all the geometrical details of the specimen used for the experiment and also the load application mode (ten-point bending) and the mechanical characteristics of the three materials used for the restoration (marble, titanium and cementitious material). For simplicity the abacuses of the columns of the temple were simulated as cubic marble blocks. Only one quarter of the model was constructed, taking advantage of the two planes of symmetry, reducing in this way the processing time. The anchoring length of each bar was set equal to $25 \mathrm{~cm}$. The thickness of the cement layer used in practice to increase the adhesion was chosen equal to $2 \mathrm{~mm}$, in accordance to the practice adopted nowadays by the experienced technicians working for the restoration of the Parthenon temple. The free span was set equal to $\mathrm{s}=0.8 \mathrm{~m}$.

Concerning the identification of the mechanical properties of the materials, the marble and the cementitious material were simulated according to their experimentally obtained constitutive laws, while the mechanical properties of the reinforcing bars were set equal to the respective ones of the commercially available pure titanium.

The numerical model was discretised by creating a fine and uniform mesh all over the reinforcing bars, the cement layer and the epistyle using a unified element size, since these parts of the model were, for the specific problem, the regions of highest interest (Figure 7). For the remaining part of the model (supporting abacuses) a coarser and uniform mesh was created. The final model consisted of about 23,500 elements.

Two couples of 3-D contact elements were created in an effort to simulate the architrave-toabacus and the marble-to-cement contact. The titanium bar was considered fully bonded with the marble. Apart from these two couples, two more couples were created: One between the central cross section area of the architrave and a new absolutely rigid area placed at the central cross section (in an effort to reproduce successfully the symmetry of the model along the axial $\mathrm{x}$-axis direction) and a second one between the lower bases of the supporting abacuses and the metallic plates placed on the ground (on which the abacuses rested during the experimental procedure).

The boundary conditions ensured the static determinacy of the actual structure taking into

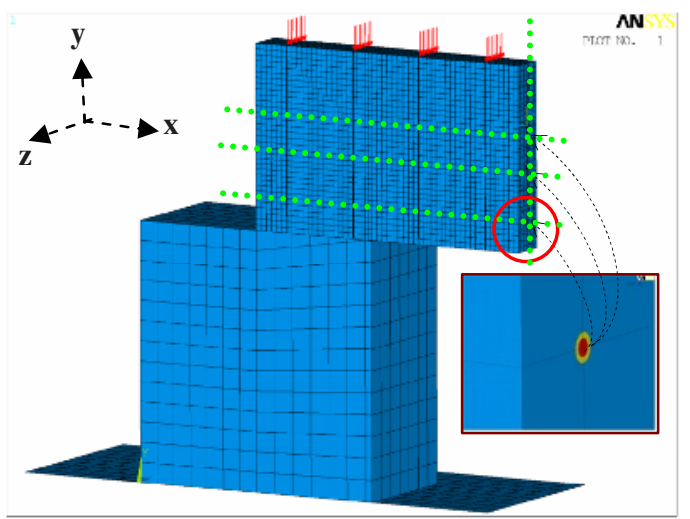

Fig. 7. An overall view of the meshing model. The embedded figure shows a detailed view at the region around the lower layer of the reinforcement. account the symmetries mentioned. Analytically:

- The central cross section of the architrave was restricted only along the right horizontal direction.

- The degrees of freedom of the central cross section of the titanium bar were restricted so that only motion along the vertical direction was permitted.

- The whole model was restricted along the direction of its thickness. 
The total load exerted was equal to 430 $\mathrm{kN}$. It was distributed along eight lines on the upper side of the architrave, as it is shown in Figure 7, in an effort to simulate the experimentally load application mode.

The analysis enlightened some interesting points concerning the distribution of the stress- and strain-field components. In Figure 8 the variations of the normal axial and transverse strains are plotted along the vertical line of the central cross section of the architrave at the position where the reinforcing bars are placed (vertical dotted line, Figure 7). Negative axial and positive transverse strains are observed for the upper one third of the section. Then these values are almost zeroed at the regions just above and below the titanium bars, indicating that at these regions the contact of the two constituent parts of the architrave is lost. In the immediate vicinity of each reinforcing bar both normal strains increase very abruptly. From this point on the strains become zero since below the lowest reinforcement layer the contact of the two constituent parts of the structural element is again lost.

As a last step the variation of the von Mises equivalent stress along the horizontal lines passing through the axes of the reinforcement layers (three horizontal dotted lines, see Figure 7) is plotted in Figure 9. Point $(0,0)$ corresponds to the leftmost point of the architrave, while point $(1,0)$ is its central point. The $1^{\text {st }}, 2^{\text {nd }}$ and $3^{\text {rd }}$ titanium layers correspond to the ones positioned at distances 7,20 and $30 \mathrm{~cm}$ from the bottom side of the architrave respectively. It is clearly seen that the almost zero initial stress values increase rapidly as one moves towards the points having the same abscissa with the corners of the supporting abacuses. It is remarkable that the $1^{\text {st }}$ layer sustains much higher stress

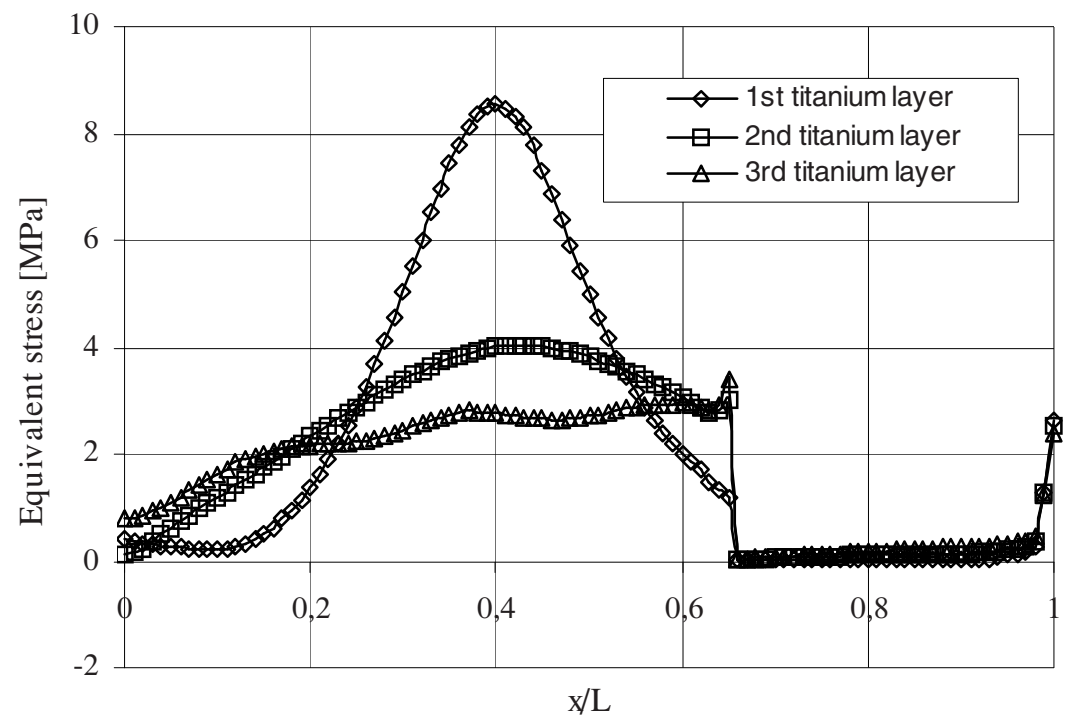

Fig.9. The variation of the von Mises equivalent stress along the horizontal lines passing through the axes of the reinforcement layers. 
values, and the overall picture of the distribution is different from that of the other two layers. This can be explained since this layer is placed closer to the bottom side of the epistyle and therefore it is easier to be influenced by the supporting abacuses. Then the equivalent stress decreases (to almost zero) for all three layers and only very close to the central cross section (point $(1,0)$ significant stress concentrations appear (in any case much lower compared to the respective ones observed above the corners of the supporting abacuses).

\section{Conclusions}

The mechanical behaviour of fractured marble epistyles restored with three series of bolted titanium bars was studied both experimentally and numerically, in an effort to assess the method used for the calculation of the reinforcement (number of titanium bars) required for the restoration of the member. The experimental study revealed that the method is rather adequate since the architrave behaved as an intact structural member (of lower, however, stiffness) for loads well above from the ones assumed to be carried by the specific member after it will be placed in its initial position. It was, also, concluded that, in spite of the presence of the cementitious material between the marble and the metal, sliding of the reinforcing bars was not avoided completely. It is thus indicated that the composition of the interposed layer should be studied further in the direction of improving its adhesion with the marble). Finally it was verified that part of the epistyle resting on the abacuses tends to lift up losing contact from the supporting abacus.

On the other hand the numerical analysis permitted the accurate description of the stress and strain fields all over the volume of the member and especially in the vicinity of the reinforcing bars. It was concluded that high stress concentrations appear in three regions of the model: At the central section around the bars, at the cross corners of the supporting abacuses and at the upper side of the epistyle in the vicinity of the central section. In addition it was indicated that the lowest layer of the reinforcing bars is under more intense stress field. Also the normal strains developed at the central cross section, both axial and transverse, attain non-zero values only along the upper third of the height of the beam. For the remaining two thirds the normal strains are negligible (with only exception the immediate vicinities of the bars) since the contact of the constituent parts is lost in this region. The above conclusions are clearly exhibited in Figure 10, where the distribution of the von Mises equivalent stress and the deformed shape (exaggerated) of the member is shown for the whole volume of it (for clarity reasons a single layer of reinforcing bars was used for the specific representation). The loss of contact both above and below the bar is to be noted.

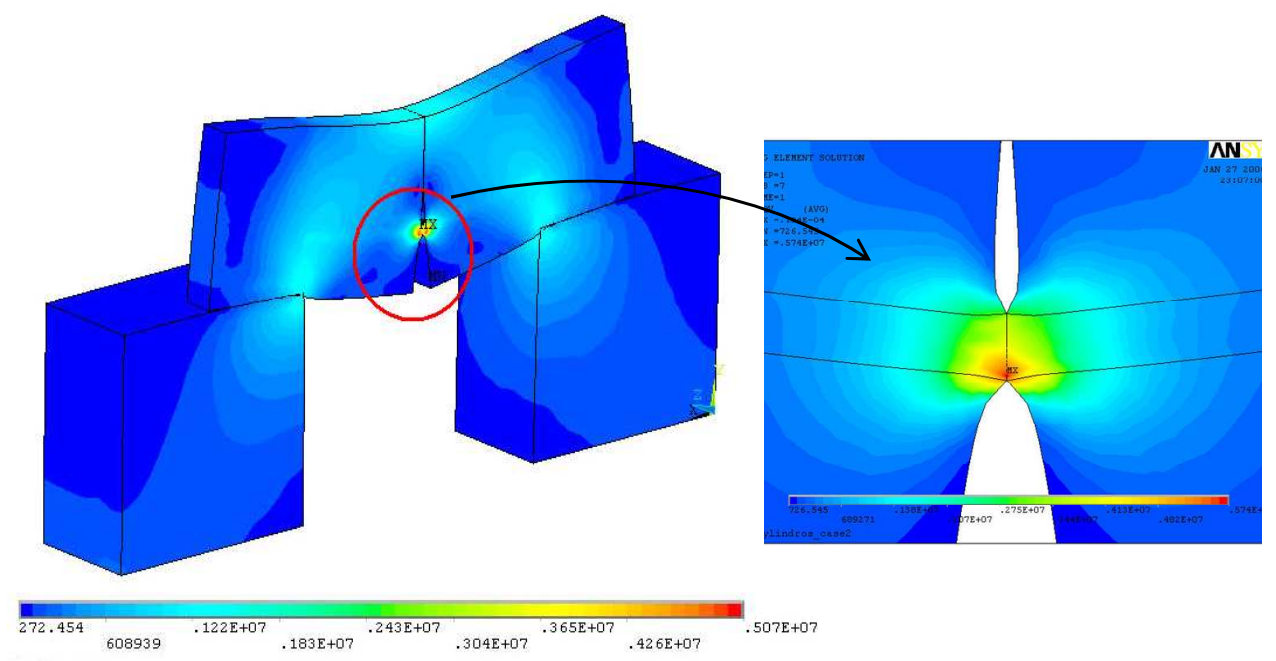

Fig.10. The variation of the equivalent stress all over a model with a single reinforcing bar. 
Concluding it is emphasized that the restoration of structural members depends on too many additional parameters like for example the geometrical features of the thread and obviously the degree of damage of the original material. Therefore it is evident that the results of the present study are only indicative. The final decisions, concerning the optimum combination of the parameters, can only be made by the scientists and technicians working for a given restoration project since they are the only ones who have an overall view of the specific problem they deal with.

\section{Acknowledgments}

The authors would like to express their sincere gratitude to Mr George Ferentinos (K. Liontos and Associates, Ansys Channel Partners of Greece) for his valuable comments and continuous support during the preparation of the numerical models. The help of Dr Panagiotis Chatzistergos of the National Technical University of Athens in the numerical simulations is acknowledged. Finally the assistance of Mr. Ignatios Chiou, technician of the work-site of the Parthenon temple, during the preparation of the specimen is also kindly acknowledged.

\section{References}

1. C. Zambas, M. Ioannidou, A. Papanikolaou, Proc. IIC Congress on Case Studies in the Conservation of Stone and Wall Paintings, Bologna, The International Institute for Conservation of Historic and Arstistic Works, 138-143 (1986)

2. C. Zambas, Structural problems of the restoration of the Parthenon, Athens, Committee for the Preservation of the Acropolis Monuments, Vol.2 $\alpha$ (1989)

3. C. Zambas, Structural problems of the restoration of the Parthenon, Athens, Committee for the Preservation of the Acropolis Monuments, Vol.3b (1994)

4. M. Ioannidou, V. Paschalides, Proc. of the $5^{\text {th }}$ Int. Symp. for the Restoration of the Acropolis Monuments, edited by F. Mallouchou-Tufano (Committee for the Preservation of the Acropolis), Athens, 291-300 (2002)

5. M. Mentzini, Proc. of the $5^{\text {th }}$ Int. Symp. for the Restoration of the Acropolis Monuments, edited by F. Mallouchou-Tufano (Committee for the Preservation of the Acropolis), Athens 233-242 (2002)

6. S. K. Kourkoulis, E. Ganniari-Papageorgiou, M. Mentzini, Heritage, Weathering and Conservation (HWC-2006) Conference, Madrid, Spain, Published in "Heritage, Weathering and Conservation', edited by R Fort et al., Balkema, The Netherlands, 657-665 (2006)

7. S. K. Kourkoulis, E. Ganniari-Papageorgiou, Engineering Transactions, 56, 159-180 (2008)

8. E. Ganniari-Papageorgiou, Strain, 45, 445-455 (2009)

9. S. K. Kourkoulis, E. Ganniari-Papageorgiou, M. Mentzini, Engineering Geology, doi: 10.1016/ j.enggeo.2009.06.012 (2009)

10. S. K. Kourkoulis, E. Ganniari-Papageorgiou, Journal of Cultural Heritage, In press (2010)

11. I. Vardoulakis, S. K. Kourkoulis, G. E. Exadaktylos, A. Rosakis, Proc. Interdisciplinary Workshop " The building stone in monuments", Athens, Eds. M. Varti-Mataranga and Y. Katsikis IGME Publishing, 187-210 (2002)

12. M. Mentzini, Archives of the General Direction of Antiquities and Cultural Heritage, A, B (2007-8) 